\title{
The Arizona State University Interplanetary Initiative: Envisioning and Creating Our Human Space Future
}

Linda T. Elkins-Tanton, Evgenya L. Shkolnik, and Michael M. Crow

Arizona State University, Tempe, Arizona, USA.

\section{ABSTRACT}

Creating a positive human space future, both beyond the Earth as well as on it, necessitates that we connect all disciplines. We need sociology, philosophy, art, and so much more, in addition to the current strong work being done in science, engineering, and law. The Interplanetary Initiative is a pan-university venture at Arizona State University that is pioneering a new model for integrated research and learning to investigate, communicate, and define our human space future. We connect the private sector, universities, and government, and we train students how to solve problems and create knowledge in teams as both leaders and collaborators. In our 3 years of operation, we have created an experimental innovative team-building research process, seed-funded $\sim 20$ interdisciplinary projects, which have included $>250$ active team members and 20 outside partners, and in 2019 achieved $\sim 11 \times$ return on investment in external funding.

Keywords: interdisciplinary, seed funding, education

\section{CONCEPT AND GOALS: ALL DISCIPLINES, ALL SECTORS PRODUCE OUR SPACE FUTURE}

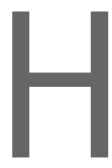

umans are becoming an interplanetary species. Much of the disciplinary focus now is on engineering: building the rockets, the transport, the habitation, and the communications. But to be a successful interplanetary species, we need to bring all disciplines to bear on this process.

We need sociologists, psychologists, educators, artists, political scientists, philosophers, economists, and so much more. We also need all sectors of endeavor, such as government and university researchers and the private sector, including corporate, religious, and civic leaders, and everyone driven to see what we can be as we embark on our greatest explorations.

At Arizona State University (ASU) we have created the Interplanetary Initiative, a pan-university venture that is pio- neering a new model to connect these disciplines and these sectors and accelerate progress and advance our human space future (Fig. 1). The goals of the Interplanetary Initiative are to

- create a new functional organizational model that brings together all stakeholders in the space sector;

- use the organization to form interdisciplinary partnerships that identify and fulfill essential needs for space exploration; and

- invent new interdisciplinary educational programs to create the workforce of the future.

Inventing the culture and community that allows diverse interdisciplinary teams to rapidly create solutions requires improvements to teaching, learning, teamwork, leadership, and connectivity of the university to the community. The innovations with which we are experimenting can drive a more effective more connected research and education enterprise.

We create our research and education teams by inviting all who are interested from across and outside the university. Interplanetary Initiative is not an academic unit, that is, professors do not have their tenure home in the initiative. We have people from $>50$ ASU units and 20 companies and government laboratories involved in the work.

\section{PILOT PROJECTS}

This initiative has aspects of a testbed, a rapid prototyping center, for concepts of a new university model. How do we drive research forward most efficiently? How do we best build teams? How can we educate for the workforce? Our model is egalitarian question-driven knowledge creation, rather than individual investigator-led research.

The kickoff meeting for Interplanetary Initiative was in January 2017, and was the first test, the first iteration, of our team-building process.

\section{The Big Question Research Team Process}

The traditional academic research model is the "hero" model, in which 1 person has the primary idea and leads the subsequent project. This model has been effective for a millennium, 


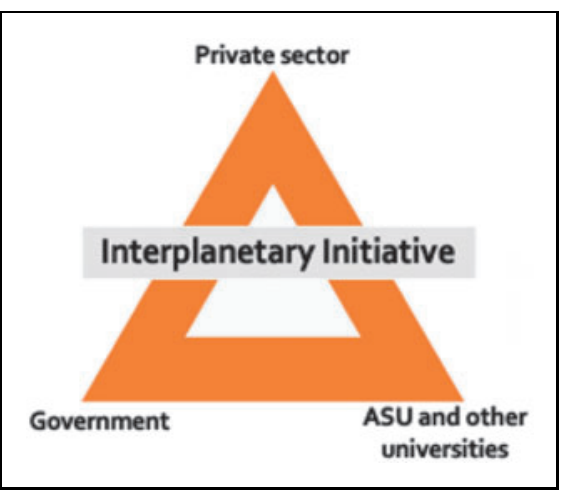

Fig. 1. The Interplanetary Initiative is designed to bridge sectors and drive progress faster. ASU, Arizona State University.

but it comes with some shortcomings: research within a single traditional discipline can be slower and more incremental than necessary; research may not be optimized for larger societal goals; and competition within and between teams can distract from goals (Table 1).
In response to these challenges, we have developed a research team-building process:

1. Bring together a diverse group of people interested in a common topic.

2. Conduct a brainstorming exercise to create a list of the largest questions that need to be answered. These are the big questions, and they may not be answerable within a single laboratory or career.

3. Group votes on these questions to select the most important to pursue.

4. Invite the group members to join one or more of the teams pursuing the selected questions in a rapid organization exercise.

5. Each question group develops outcomes and products possible in 1 year, the necessary milestones, and all disciplines needed for success.

6. Each group selects a leader.

7. After the meeting, each group finds the needed additional team members and creates a budget and greater

\begin{tabular}{|c|c|c|c|}
\hline $\begin{array}{l}\text { Aspects of the Traditional } \\
\text { University Model }\end{array}$ & Challenges This Model Creates & $\begin{array}{l}\text { Goals for the Solutions } \\
\text { to These Challenges }\end{array}$ & $\begin{array}{l}\text { Solutions the Interplanetary } \\
\text { Initiative Is Testing }\end{array}$ \\
\hline $\begin{array}{l}\text { Research is driven by university } \\
\text { timelines }\end{array}$ & $\begin{array}{l}\text { Difficult to match urgency of timeline to industry } \\
\text { needs }\end{array}$ & Seamless partnerships across sectors & $\begin{array}{l}\text { Project management for all partnered } \\
\text { research }\end{array}$ \\
\hline Education is content driven & $\begin{array}{l}\text { "Sacred content" for each discipline leaves little time } \\
\text { for teaching transferrable skills } \\
\text { Lectures are demonstrated to be a poor teaching } \\
\text { tool } \\
\text { Education is poorly coupled with workforce needs }\end{array}$ & $\begin{array}{l}\text { Students prepared for work and life: } \\
\text { problem solvers with a sense of agency } \\
\text { Key graduate student skills are taught } \\
\text { to undergraduates (critical thinking, } \\
\text { self-determination, and problem } \\
\text { solving) }\end{array}$ & $\begin{array}{l}\text { Design education around transferrable } \\
\text { skills such as collaborative problem } \\
\text { solving } \\
\text { Reward instructors for moving beyond } \\
\text { the pure lecture model } \\
\text { Mix undergraduates and graduates in } \\
\text { the same classrooms }\end{array}$ \\
\hline
\end{tabular}


detail on their milestones and outcomes. This activity demonstrates whether the group is functional and has a strong leader.

8. The group proposes to pursue a question, and if funded, is placed under professional project management.

About 60 people participated in our kickoff meeting in January 2017. They included university faculty, staff, and students, people from the private sector, and people from the general community. Some of the Big Questions we considered in that and later meetings include the following:

- What are the necessary rules of law, governance models, and enforcement mechanisms for free and peaceful uses of space?

- How will we make the space experience and data available to the public?

- How do we expand the human presence in space responsibly? Who decides?

- What are the most effective arguments for pursuing human space exploration?

- What Earth infrastructure do we need to support offEarth settlement?

- How can we better connect human and robotic exploration?

- What does past exploration tell us about future exploration?

-What is the business model for interplanetary exploration?

In May 2017 we funded our first 8 pilot projects. The teams did not disperse over the summer or prioritize the work at a low level. To our surprise and joy, we had our first peer-reviewed article published in September 2017. In the next year, FY19, we had 13 active pilots involving 115 team member and 8 corporate partners.

Since then our cumulative project total has risen to 20 with 250 team members and 20 external partners. Some pilots have been completed, and some have grown with outside funding. In addition to the Big Question pilots, we have focused technology pilots and education pilots. And over the second year of seed-funded pilots, return in total external grant dollars as a function of total pilot seed funding is about 11 times.

Our projects include

- robotic exoskeleton prototypes for enhancing human activity in space;

- a multiplayer game that collects social science data on behavior in competing off-world settlements;

- a scalable computer model of an off-world community;

- a new 3-year undergraduate bachelor of science degree focused on creating collaborative problem solvers launching in Fall 2020;
- a space business advisory and legal clinic;

- a new process and series of meetings focused on international lunar policy and governance;

- early concepts for advanced water and volatile recovery on the Moon;

- student project launches on Blue Origin's New Shepard; and

- framework and mission plans for rapidly redeployable spacecraft.

\section{EDUCATION PROJECTS}

The education efforts of the Interplanetary Initiative lie in three areas:

1. Exploration Learning: The Interplanetary Initiative convenes workshops on inquiry and exploration learning to gather best practices and spread them across the university.

2. Partner programs: In partnership with Qwaltec we recently launched the first course in the world's first online satellite command and control certificate. This and future programs will serve workforce development and training.

3. The Bachelor of Science in Technological Leadership: Training in leadership thinking and solving scienceand technology-related open problems, which is a skill required for the new fields of the future, for successful leadership, and for graduate school.

A disconnect exists between many university degree programs and the workforce: the students are being taught content that is sometimes but not always relevant for their future work, but they are not being explicitly taught how to recognize unsolved problems, how to pursue solutions to those problems, how to give and take feedback, and how to work in teams, the key skills for success in any job.

The Technological Leadership Bachelor of Science is a scalable 3-year degree program using Exploration Learning techniques in the classroom and designed specifically to connect to industry internships over the summer and job readiness on graduation. Every student will learn statistics, calculus, and coding, in addition to collaborative problem solving, team building and communication, and critical thinking, through the new educational methodologies we have developed.

The heart of this major is 2 classes that every student takes every semester. We call them "thinking" and "making." In the thinking classes, students practice researching and stepping along a solution path of a big science- or technology-oriented question. Examples from past planetary-focused classes include "What will the Moon look like after settlement?" 


\section{ELKINS-TANTON ET AL.}

"How will we support a human biosystem, in space?" "How will we discover life off of the Earth and what should we do when we discover it?" Students learn to ask productive questions, do research, and distill information for the team. In the making courses, students build projects associated with planetary space missions, or with computer-aided design, and thus learn problem solving outside the classroom as well.

\section{THE FUTURE}

The undergraduate degree starts in August 2020. Our space hardware build-and-test laboratory opened in December 2019. This space is dedicated to projects with outside partners. In the coming year we will continue to test the team and education models, and we will build our partnerships.

To speed research and development, to create an effective workforce, to produce highly functional interdisciplinary teams, we need to test and advance new processes. The ASU Inter- planetary Initiative is acting as a sandbox for the creation of new processes, and our goal is to bring together the stakeholders for human space futures and speed up our progress.

\section{AUTHOR DISCLOSURE STATEMENT}

No competing financial interests exist.

\section{FUNDING INFORMATION}

The Arizona State University Interplanetary Initiative activities described in this paper have been funded by the university.

Address correspondence to:

Linda T. Elkins-Tanton

Arizona State University

ISTB4, 781 Terrace Road

Tempe, AZ 85287

USA

E-mail: ltelkins@asu.edu 